\title{
Tobacco point of sale advertising increases positive brand user imagery
}

\section{R J Donovan, J Jancey, S Jones}

See end of article for authors' affiliations

......................

Correspondence to: Professor Rob Donovan Division of Health

Sciences, Executive Dean's

Suite, Bldg 400, Curtin

University, Hayman Rd

Bentley WA 6102

Australia;

r.donovan@curtin.edu.au

Received

27 December 2001

and revision requested 7

February 2002

Accepted 10 May 2002

\begin{abstract}
Objectives: To determine the potential impact of point of sale advertising on adolescents so as to inform changes to the Tobacco Control Act.

Design: Participants were randomly assigned to one of two conditions. In the control condition, students were exposed to a photograph of a packet of cigarettes; in the intervention condition, students were exposed to an ad for cigarettes, typical of point of sale advertising posters. All students then rated the brand user on a set of 12 bipolar adjectives. Two brands were used in the study: Benson \& Hedges, and Marlboro.

Subjects: One hundred year (grade) 6 and 7 students (age range 10-12 years), from four Western Australian metropolitan primary schools, participated in the study.

Results: In a majority of the brand user descriptions, the cigarette advertisements increased brand user imagery in a positive way, especially for Benson \& Hedges. For example, participants viewing the Benson \& Hedges advertisement, as distinct from those viewing the Benson \& Hedges pack only, were more likely to describe the Benson \& Hedges user as relaxed, interesting, cool, rich, adventurous, and classy. Relative to the Marlboro pack only, the Marlboro ad increased positive perceptions of the Marlboro user on adventurous, interesting, and relaxed.

Conclusions: The results presented here support restrictions being placed on advertising at point of sale, since such ads have the potential to increase positive brand user imagery directly in the situation where a product purchase can take place, and hence the potential to increase the likelihood of impulse purchasing.
\end{abstract}

A dolescent smoking rates have levelled out in many countries, but appear to be increasing in others. ${ }^{12}$ It has been estimated that in Australia, 20000 teenagers commence smoking each year, ${ }^{3}$ and in the USA this figure is close to one million. ${ }^{3}$ In both countries, almost $90 \%$ of smokers commenced smoking before the age of $18 .{ }^{24}$ Of those who smoke daily in high school, it is projected that $75 \%$ will still be smoking 7-9 years later, and one third of these early starters will die from tobacco related causes. ${ }^{5}$

Although the tobacco industry claims that tobacco advertising and promotion are not aimed at those under age, it is widely accepted that cigarette advertising and promotion play a part in children's decision to smoke. ${ }^{6-10}$ The industry argues that, far from encouraging the uptake of smoking, its primary purpose is to encourage adults to switch brands. ${ }^{11}$

Innovative studies that have utilised pictures of brand names and logos have shown that children as young as 3 years old can correctly recognise logos and understand advertisements, ${ }^{12}$ with up to $90 \%$ of US 6 year olds being able to recognise the cartoon character Joe Camel. Other studies using similar techniques have shown that tobacco advertisements are widely recognised by young children, with primary school children being able to identify cigarette brands from advertisements in which the brand names were obscured..$^{13} \mathrm{~A}$ similar study found that exposure to and awareness of tobacco advertisements are positively correlated with adolescent smoking. ${ }^{14}$

Cigarette brand advertising and promotion are characterised by "user imagery" creative tactics. ${ }^{15}{ }^{16}$ It is felt that young people are particularly vulnerable to such advertising, as it contributes to self identity. ${ }^{17}$

Point of sale advertising

Point of sale advertising has become an established means of targeting consumers. The Point of Purchase Advertising Insti- tute, an industry trade group in the USA, asserts that point of sale advertising is designed to target consumers at the place where they will buy the product, drawing shoppers' attention to the advertised brand when they are in the buying mood. It has been found that tobacco impulse purchases increase by as much as $28 \%$ when displays are present. ${ }^{18}$

An indication of how effective point of sale advertising can be has been demonstrated by Rothmans in Australia with their deck chair display for their Holiday brand. The deck chair display was produced for placement in $50 \%$ of tobacco outlets. Market share growth after two staggered six week campaigns over a nine month period achieved a $1.2 \%$ increase for the brand, from $7.0 \%$ to $8.2 \%$ of total industry sales. ${ }^{19}$

With the lucrative return that can be generated from point of sale advertising, and restrictions on other forms of advertising, it is not surprising that the tobacco industry is diverting large sums of money into this promotional avenue. It has been estimated in Australia that tobacco companies are spending as much as A\$15 000 per retail outlet, extending the shop floor area and enabling primary placement of their products. There is no cost to retailers involved, who are merely obliged to provide primary placement of tobacco products for a fixed period. These new and extended counters and display units allow the store to carry and display a quantity of stock that far exceeds demand. ${ }^{20}$ In 1999, The Point of Purchase Advertising Institute awarded its "Permanent Display of the Year" award to RJ Reynolds Tobacco for its Camel trade store program. $^{21}$

With no restrictions at point of sale, cigarettes are placed in the corner store alongside soft drinks, lollies, and chewing gum, all products that are innocuous and appeal to the young consumer. A recent survey of tobacco promotion awareness among 15 and 16 year olds in north east England found that $100 \%$ of the 629 young people surveyed had seen point of sale marketing for cigarettes. ${ }^{22}$ 


\section{Tobacco control legislation and point of sale} As the 2006 European Union ban on overt promotion of tobacco products draws nearer, marketing experts have "warned" that point of sale will become the last avenue for brand building by the tobacco industry. Similarly, in the UK, the Tobacco Advertising and Promotion Bill being debated in the Lords seeks to ban all tobacco promotion except point of sale. $^{23}$

Last year, two pieces of Massachusetts legislation which aimed to curb the use of point of sale tobacco promotions within that state were overturned by the US Supreme Court ${ }^{24}$ on the grounds that they were unconstitutional. Importantly, these pieces of legislation, which were aggressively fought by the tobacco and advertising industries, did not provide for a total ban on point of sale, but merely limited it to being more than 1000 feet $(300 \mathrm{~m})$ from schools and playgrounds, being at least five feet $(1.7 \mathrm{~m})$ off the ground, and banning giveaways. $^{25}$

Within Australia, as for the US, legislation varies between states. In New South Wales, for example, point of sale promotions of tobacco products were banned with effect from 31 August 1999. ${ }^{26}$ In Western Australia, the Tobacco Control Act 1990 severely restricts tobacco sponsorship, advertising, and promotion; prohibits competitions, inducements, free samples, and merchandise along with promotion of tobacco products; makes selling tobacco to persons under 18 years of age a criminal offence; and limits the location of vending machines. A review of the Act in 1995 found that a major area of concern related to point of sale advertising in retail outlets and recommended prescribing the number, size, and placement of tobacco advertisements that may be inside a shop or retail outlet. They also recommended that the definition of a dispensing unit be changed to be more prescriptive. ${ }^{27}$ However the government has failed to act upon the recommendations.

The Health Department of Western Australia estimates that there are over 4000 outlets selling cigarettes throughout the state. If Australian teenagers visit such stores as frequently as their US counterparts (three out of four teenagers shop at convenience stores at least once a week ${ }^{12}$ ) it means that adolescents are continually exposed to point of sale advertising.

Point of sale represents an effective advertising avenue for tobacco companies to promote their product and increase their market. This study aims to determine the impact of point of sale tobacco advertising on young people, as this remains one of the few avenues available to tobacco marketers, so as to ascertain the need for changes to the Tobacco Control Act.

\section{METHOD \\ Participants}

A convenience sample of 100 year (grade) 6 and 7 students (age range 10-12 years) from four Western Australian metropolitan primary schools, two with largely blue collar and two with largely white collar catchment areas, participated in the study. The school principals were approached in writing and then followed up with a telephone call requesting the participation of their years 6 or 7 in the study. All agreed, with two requiring a notification letter for the students' parents. Convenient times to conduct the research were arranged and the questionnaires were completed in the classroom under the supervision of the teacher and the researcher. One class only was selected from each school, such that two schools provided access to a year 6 class and two provided access to a year 7 class. All students present on the day of testing were included in the study.

\section{Study design}

Two brands were used in the study: Benson \& Hedges and Marlboro. Although these brands do not have a high market share among schoolchildren, they are well known among
Table 1 Percentage of children who could correctly identify the product type $(n=100)$

\begin{tabular}{lc}
\hline Product name & $\begin{array}{l}\text { Correctly identified the } \\
\text { product type (\%) }\end{array}$ \\
\hline Uncle Toby's (food) & 97 \\
Winfield (cigarettes) & 88 \\
Coca Cola (drink) & 100 \\
Peter Jackson (cigarettes) & 87 \\
Mars (food) & 99 \\
Colgate (other) & 98 \\
Milo (drink) & 99 \\
Holiday (cigarettes) & 81 \\
McDonalds (food) & 98 \\
Benson \& Hedges (cigarettes) & 83 \\
Cadbury (food) & 98 \\
Nike (other) & 99 \\
\hline
\end{tabular}

students ${ }^{2}$ (table 1; Benson \& Hedges awareness). Hence it was felt that any impact of advertising would be strong evidence for a point of sale advertising effect relative to the impact for unknown brands. The "control" condition for each brand was exposure to the cigarette pack only. The "intervention" condition was exposure to a poster ad for the brand. Randomising brands and conditions across students, the students were exposed to a photograph of a packet of cigarettes for one brand and to a poster style ad for the other brand. Hence, approximately $\mathrm{n}=50$ students were exposed to each brand in each condition. The ads used were selected from magazines published overseas but available in Australia.

\section{Questionnaire}

The questionnaire was piloted on 11 children from a non-participating school, and changes made accordingly. The questionnaire took approximately 20-30 minutes to complete and comprised three sections.

Section 1 measured recognition of 12 product brand names and logos. These were Uncle Toby's (cereal), Winfield (cigarettes), Coca Cola (soft drink), Peter Jackson (cigarettes), Mars (chocolate bar), Colgate (toothpaste), Milo (chocolate flavoured drink), Holiday (cigarettes), McDonalds (fast food), Benson \& Hedges (cigarettes), Cadbury (chocolate), and Nike (sportswear). Participants were asked to match each brand name to a product by selecting one of four categories (food, cigarette, drink, "other"), or responding "don't know". Section 2 presented the children with colour photographs of the pack of one brand and a poster advertisement for the other. The order of presentation was randomised across respondents. After viewing the pack or advertisement, they then turned the page and were asked to describe, from what they saw in the picture, what kind of people they thought smoked the brand, by selecting from each of a set of 12 adjective pairs: relaxedstressed out; boring-interesting; unhealthy-healthy; cooluncool; rich-poor; timid-adventurous; someone I would like-someone I would not like; up-to-date-out-of-date; classy-ordinary; exciting-dull; unattractive—attractive; like me-not like me.

All participants first completed a practice example using a Quiksilver clothing advertisement.

Section 3 contained general questions on where the participants had seen cigarettes advertised, their smoking habits, and their attitude to smoking.

\section{RESULTS}

There were approximately equal numbers of girls $(n=47)$ and boys $(\mathrm{n}=53)$, with the majority of the respondents being 11 years of age $(59 \%)$ ( $19 \% 12$ years; $22 \% 10$ years). Only 11 students reported "ever smoking" (only one reported smoking in the "last seven days"). 
Table 2 User imagery for Benson \& Hedges pack and advertisement

\begin{tabular}{lll}
\hline Descriptive word & $\begin{array}{c}\text { Benson \& Hedges } \\
\text { packet }(n=50)(\%)\end{array}$ & $\begin{array}{l}\text { Benson \& Hedges } \\
\text { ad }(n=50)(\%)\end{array}$ \\
\hline Relaxed** & 24 & 46 \\
Interesting*** & 18 & 44 \\
Healthy & 2 & 6 \\
Cool & 10 & 22 \\
Rich*** & 34 & 66 \\
Adventurous* & 30 & 50 \\
Someone I would like & 22 & 30 \\
Up-to-date & 50 & 44 \\
Classy & 14 & 26 \\
Exciting & 20 & 30 \\
Attractive & 18 & 24 \\
Like me & 20 & 10 \\
\hline \multirow{2}{*}{ * $<0.1,{ }^{* *} p<0.05 ; * * * p<0.01}$.
\end{tabular}

Table 3 User imagery for Marlboro pack and advertisement

\begin{tabular}{lcc}
\hline Descriptive word & $\begin{array}{l}\text { Marlboro packet } \\
(\mathrm{n}=50)(\%)\end{array}$ & $\begin{array}{l}\text { Marlboro ad } \\
(\mathrm{n}=50)(\%)\end{array}$ \\
\hline Relaxed & 14 & 26 \\
Interesting & 18 & 26 \\
Healthy & 2 & 0 \\
Cool & 10 & 12 \\
Rich & 36 & 38 \\
Adventurous* & 24 & 42 \\
Someone I would like & 20 & 20 \\
Up-to-date & 38 & 26 \\
Classy & 6 & 10 \\
Exciting & 16 & 16 \\
Attractive & 12 & 10 \\
Like me & 14 & 8 \\
\hline \multirow{2}{*}{ * $<0.1}$. &
\end{tabular}

\section{Brand identification}

Children showed almost $100 \%$ awareness for many products, such as Nike, Mars, Coke, Cadbury, and McDonalds, which are purchased and/or consumed by people in their age group. The children's awareness of cigarette products, in terms of being able to identify correctly the brand names as cigarettes, was between $81-88 \%$. This is a high level of awareness for adult products supposedly not marketed to the survey group. The results in table $\mathrm{l}$ are shown in the order they were given to the students.

\section{Influence of advertising versus pack only}

$\chi^{2}$ analyses were used to assess differences between the conditions. In a majority of the brand user descriptions, the cigarette advertisements increased brand user imagery in a positive way, especially for Benson \& Hedges (tables 2 and 3; positive adjectives only shown). For example, participants viewing the Benson \& Hedges advertisement, as distinct from those viewing the Benson \& Hedges pack only, were more likely to describe the Benson \& Hedges user as relaxed (46\% $v$ $24 \%, \mathrm{p}=0.035)$, interesting $(44 \% v 18 \%, \mathrm{p}=0.009)$, cool $(22 \% v$ $10 \%$, not significant (ns)), rich $(66 \% \vee 34 \%, \mathrm{p}=0.003)$, adventurous $(50 \%$ v $30 \%, \mathrm{p}=0.066)$, and classy $(26 \% v 14 \%, \mathrm{~ns})$. The impact of the Marlboro ad was substantially less, probably because the scene of outdoor camping was less relevant to this age group. Nevertheless, relative to the Marlboro pack only, those viewing the Marlboro ad were more likely to rate the Marlboro user as adventurous ( $42 \%$ v $24 \%, \mathrm{p}=0.0884)$, interesting $(26 \% v 18 \%$, ns), and relaxed (26\% v 14\%, ns). On the other hand, the Marlboro ad resulted in greater perceptions of the Marlboro user as out of date $(74 \% v 62 \%, \mathrm{~ns})$.

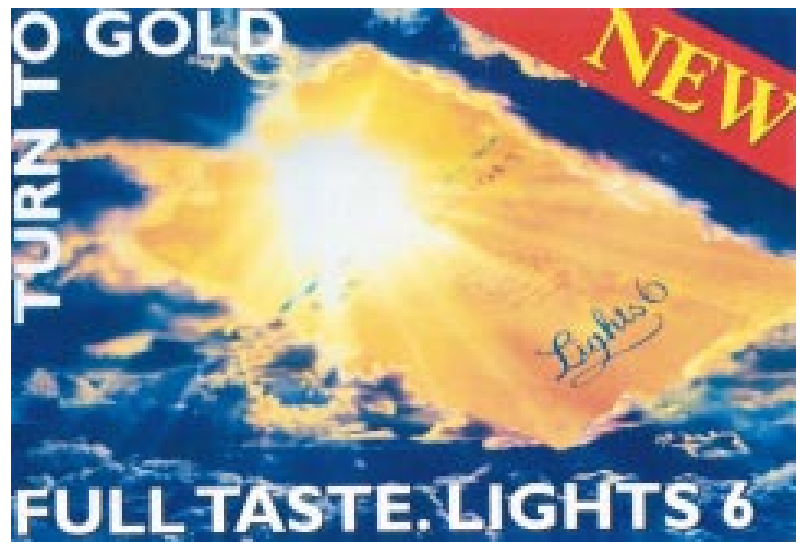

Figure 1 Benson \& Hedges advertisement.

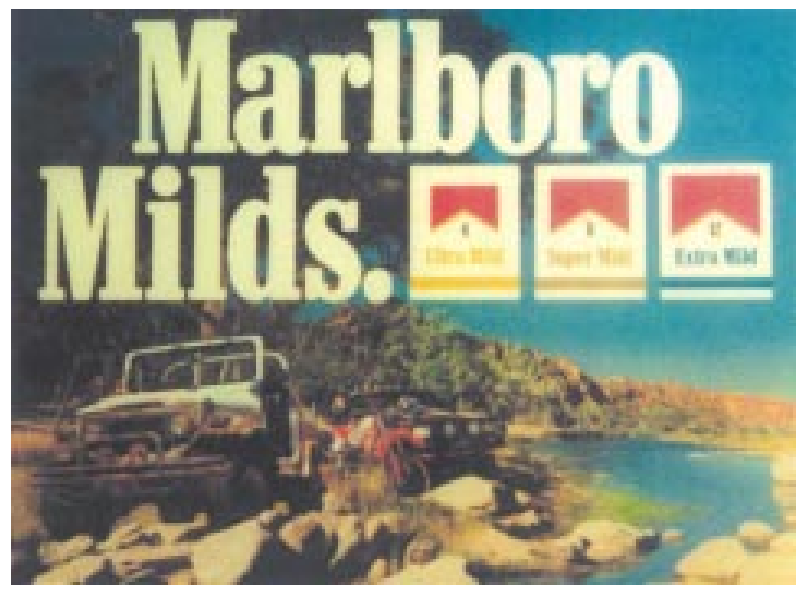

Figure 2 Marlboro advertisement.

\section{DISCUSSION}

The generalisability of these results is limited by the small sample size and by the experimental nature of the study. Nevertheless, the methodology is similar to that employed by commercial advertising researchers. These results are consistent with previous studies that show children can easily recognise product brand names and their associated products, ${ }^{12}{ }^{13}$ including cigarette brands, even though cigarettes have limited promotional avenues and tobacco companies claim that advertising is not directed at children. ${ }^{11}$

It is not surprising that companies that invest large sums of money in advertising, such as Coca-Cola and Nike, are recognised by almost all the children ( $100 \%$ and $99 \%$, respectively). What is noteworthy is that nearly 9 out of 10 children were able to recognise the names of cigarette brands, even though tobacco is supposedly an adult product and all forms of media advertising have been banned in Australia since before these children learned to read.

Children are referred to by marketing researchers as "consumers in training". Market researchers believe that brand awareness and positive brand attitudes created in childhood can be the basis for product preference later in life. ${ }^{28}$ This effect has even be shown to influence their preference for products that they are too young to use, such as lipstick and diet soft drink. ${ }^{29}$ As the tobacco industry itself acknowledges, brand preferences at adolescence tend to remain fixed for life, hence making the youth market not just attractive, but essential for tobacco marketers to remain competitive.

Brand user imagery is one of the major positioning strategies that advertisers use to create positive attitudes to their brands, and hence an increased likelihood of purchase. ${ }^{32}$ This applies also to the product category. ${ }^{32}$ This study found 


\section{What this paper adds}

There have been numerous studies of the impact of tobacco media advertising and other promotions on adolescents. However there are few studies that have attempted to assess the potential impact of point of sale tobacco advertising. This study shows that point of sale tobacco advertising has the potential to increase significantly positive brand user imagery, and hence not only adds to long term user imagery, but would increase the likelihood of impulse purchasing.

that advertising can improve a child's perception of people who use the product (user imagery). In the majority of cases, children who were shown a cigarette brand advertisement described the user more positively than those who were shown just a picture of a packet of the same brand of cigarettes. For example, when looking at a Benson \& Hedges cigarette pack, $18 \%$ of children thought the user would be an interesting person, but when they looked at the advertisement this increased to $44 \%$. This increase was noted in a range of categories, clearly indicating that point of sale advertising has the ability to impact on children's brand user imagery.

The two ads clearly had different impacts. The Benson \& Hedges ad was a surrealistic drawing (fig l) whereas the Marlboro ad depicted an outdoors adult scene (fig 2). Given today's children's visual literacy, such graphics appear to be one way tobacco advertisers can reach children without targeting them in a more direct manner that would arouse opposition. Many UK tobacco campaigns use these sorts of ambiguous (or "clever") visual images in their print and poster advertising (for example, the Silk Cut campaign).

Point of sale is obviously an excellent promotional avenue. About a third of children surveyed stated that they had seen cigarettes advertised in shops. Given that children are frequent visitors to shops, this leads to a potentially considerable amount of exposure. The results presented here, at least for Benson \& Hedges, support restrictions being placed on advertising at point of sale, since such ads can increase positive brand user imagery directly in the situation where a product purchase can take place. Hence impulse purchases are more likely in such situations than where point of sale ads do not exist. Even if a purchase is not or cannot be made, exposure to the advertising increases user imagery and hence a positive predisposition towards the product for purchase at a later date. In short, the results presented here are precisely what any commercial advertiser would hope to see-that is, evidence that their point of sale advertising works!

\section{ACKNOWLEDGEMENTS}

The Centre for Behavioural Research in Cancer Control is part funded by the Cancer Foundation of Western Australia. Konrad Jamrozik provided advice on the project.

\section{Authors' affiliations}

R J Donovan, *J Jancey, †S Jones, Centre for Behavioural Research in Cancer Control, Division of Health Sciences, Curtin University of Technology, Hayman Rd, Bentley, Western Australia, Australia

*Formerly Australian Council on Smoking and Health, Subiaco, Western Australia

†Now at the Graduate School of Public Health, University of Wollongong, NSW, Australia

\section{REFERENCES}

1 Winstanley M, Woodward S, Walker N. Facts and issues: 1995. Victoria: Victorian Smoking and health Program, 1996.

2 Anti Cancer Council of Victoria. Cigarette consumption among 12-17 year old Western Australian school students in 1996 Summary report. Perth, Australia: Health Department of WA and Centre for Behavioural Research, 1997.

3 Hill D, White V, Segan C. The prevalence of cigarette smoking among Australian secondary school children in 1993. Aust J Public Health 1995; 19:445-9.

4 Novelli WD. "Don't smoke," buy Marlboro. BM 1999;318:1296.

5 Giacopassi D, Vandiver M. University students' perceptions of tobacco, cocaine, and homicide fatalities. Am J Drug Alcohol Abuse 1999;25: 163-72

6 Pierce JP, Choi WS, Gilpin EA, et al. Tobacco industry promotion of cigarettes and adolescent smoking. JAMA 1998;279:511-6.

7 Pierce JP, Gilpin EA, Choi WS. Sharing the blame: smoking experimentation and future smoking-attributable mortality due to Joe Camel and Marlboro advertising promotions. Tobacco Control 1999:8:37-44.

8 Rigotti NA, Difranza JR, Chang Y, et al. The effect of enforcing tobacco sales laws on adolescents' access to tobacco and smoking behaviour. N Engl J Med 1997;337:1044-51

9 Smee C. Effects of tobacco advertising on tobacco consumption: a discussion document reviewing the evidence. London: Department of Health, 1992.

10 US Department of Health and Human Services. Preventing tobacco use among young people. A report of the Surgeon General, 1994. Atlanta, Georgia: Public Health Service, Centers for Disease Control and Prevention, Office on Smoking and Health, 1994. (US Government Printing Office Publication No S/N 017-001-00491-0.)

11 Leiss W, Kline S, Jhally S. Social communication in advertising. Scarborough, Ontario: Nelson Canada, 1990.

12 Fischer $M$, Meyer $P$, Schwartz MD, et al. Brand logo recognition by children aged 3 to 6 years. JAMA 1991;266:3145-8.

13 Peter J, Betson C, Hedley A, et al. Recognition of cigarette brand names and logos by young children in Hong Kong. Tobacco Control 1995:4:150-5.

14 Unger J, Johnson C, Rohrbach L. Recognition and liking of tobacco and alcohol advertisements among adolescents: Relationships with susceptibility to substance use. Prev Med 1995;24:461-6.

15 Chapman S. Great expectorations: advertising and the tobacco industry. London: Comedia, 1986.

16 Klein N. No logo. London: HarperCollins, 2000.

17 Cushman P. Why the self is empty. American Psychologist 1990;45:599-611.

18 Rogers T, Feighery RN, Tencati E, et al. Community mobilization to reduce point of purchase advertising of tobacco products. Hlth Educ Qrtly 1995;22:427-42.

19 Sweeting G. Aussies awarded for effective displays. Ad News 1998;27 March:37.

20 Minter, Ellison, Northmore, et al. Additional recommendations for amendments to the summary of the recommendations made by Minter, Ellison, Northmore and Hale in the Review of the Tobacco Control Act, 1995.

21 Thompson S. And the winner for merchandising achievement is .... Brandweek 1999;40:50.

22 MacFadyen L, Hastings G, MacKintosh AM. Cross sectional study of young people's awareness of and involvement with tobacco marketing. BM 2001;322:513-7.

23 Thurtle G. Tobacco lobby hatches plot to neuter ad ban in Lords. Marketing Week 2001;April 5:5

24 Teinowitz I. Supremes sink mass. Ad curbs. Advertising Age $2001 ; 72: 3,26$.

25 Teinowitz I. Tobacco cases worry ad groups. Advertising Age $2001 ; 72: 17$

26 Ban E. Tough tobacco ruling shocks retail industry. Retail World 1999;52:4.

27 Minter, Ellison, Northmore, et al. Review of the operation of the Tobacco Control Act: Final report (prepared for the Minister of Health), 1995.

$28 \mathrm{McNeal} \mathrm{JU}$. Children as consumers. Lexington, Massachusetts: Lexington Books, 1987.

29 Gorn GJ, Florsheim R. The effect of commercials for adult products on children. J Consumer Res 1985;11:962-7.

30 Perry L. The tobacco industry and underage youth smoking: tobacco industry documents from the Minnesota litigation. Arch Ped Adol Med 1999; 153:935-41.

31 Collishaw N. The story of Player's Lights. Paper presented at the World No-Tobacco Day Forum on Tobacco Industry Documents, Ottawa, Canada, 31 May 2000.

32 Rossiter JR, Percy, L. Advertising communications and promotion management. New York: McGraw-Hill, 1997. 